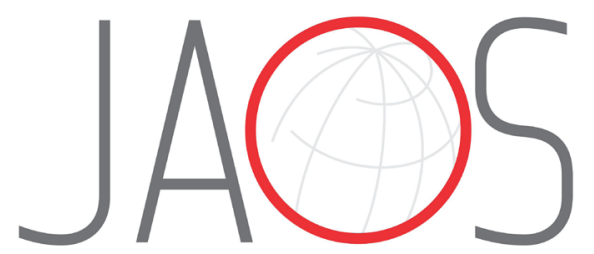
JOURNAL OF APPLIED ORAL SCIENCE

\title{
The effect of solution and gel forms of sodium hypochlorite on postoperative pain: a randomized clinical trial
}

\section{Abstract}

Esin OZLEK ${ }^{1}$

Hüseyin GUNDUZ1

Gizem KADI ${ }^{1}$

Ahmet TAŞAN ${ }^{1}$

Elif $\mathrm{AKKOL}^{2}$ iD
Objectives: The aim of this study is to evaluate the effect of using gel and solution forms of $\mathrm{NaOCI}$ during the chemomechanical preparation of the root canals on postoperative pain at different time intervals. Methodology: 114 patients with mandibular molar teeth and symptomatic irreversible pulpitis were included in the study. All patients were divided into two groups based on the irrigant used during root canal preparation $(n=57)$ : Group 1, 5.25\% NaOCI, Group 2, 5.25\% NaOCI gel. All groups were filled with gutta-percha and $\mathrm{AH}$ Plus root canal sealer using single-cone technique. VAS scale (1-10) was used for postoperative pain assessment. After endodontic treatment, all patients were asked to record their postoperative pain levels at the 6th, 24th, 48th, 72nd hours, and 1 week later. The data were analyzed using ChiSquared, Independent Samples T, Cochran Q and Friedman tests. Results: Statistically significant difference was not found between the distributions of pain levels at different times according to the groups ( $p>0.050)$. A statistically significant difference was observed between the distributions of pain levels measured at different times in the solution group $(p<0.001)$. A statistically significant difference was found between the distributions of pain levels measured at different times in the gel group $(p<0.001)$. In both groups, highest postoperative pain levels occurred in the first 6 hours. Pain levels of the gel group as 38,5\% mild, $17.3 \%$ moderate, $5.8 \%$ severe and pain levels of the solution group were obtained as $46.2 \%$ mild, $26.9 \%$ moderate, 9.6\% severe at the 6 th hour. Conclusions: The use of the gel form of $\mathrm{NaOCI}$ during the chemomechanical preparation of the root canals showed similar postoperative pain when compared to the solution form.

Keywords: Postoperative pain. Root canal irrigants. Root canal preparation. Sodium hypochlorite gel. Sodium hypochlorite solution.
Submitted: December 1, 2020 Modification: April 19, 2021 Accepted: April 21, 2021
Corresponding address: Esin Ozlek

The University of Van Yuzuncu Yil - Faculty of Dentistry - Department of Endodontics - Van - Turkey. Phone: +905305200059 e-mail address: e.ozlek@yyu.edu.tr
${ }^{1}$ The University of Van Yuzuncu YIl, Faculty of Dentistry, Department of Endodontics, Van, Turkey. ${ }^{2}$ Medicadent Oral and Dental Health Clinic, Istanbul, Turkey. 


\section{Introduction}

Postoperative pain is a widespread complication after root canal treatments, which is undesirable for patients and physicians. ${ }^{1}$ The incidence of postoperative pain stated in cases is $39 \%$ after endodontic treatment and in the first 24 hours, this rate can even be up to $65 \%$ and above. ${ }^{2}$ Many mechanical, chemical and microbiological factors play a role in the occurrence of postoperative pain. ${ }^{3}$ It especially appears as a result of extrusion of noninfected debris and solutions into periradicular tissues. ${ }^{4}$ Many studies about this subject exists in the literature. ${ }^{1}$ These studies have focused on different irrigation solutions and activation systems in addition to the mechanical preparation procedures of the root canal. 5,6

Sodium hypochlorite $(\mathrm{NaOCI})$ is the most widely used irrigation solution during root canal treatment. ${ }^{3}$ In addition to its advantages such as antimicrobial activity and organic tissue solvency, however, it also has cytotoxic effects on periradicular tissues. When it is extruded from apical to periradicular tissues during root canal treatment, it damages endothelial cells and fibroblasts, facial nerve palsy, allergic reaction and necrosis may develop. ${ }^{7}$ In a retrospective study conducted by members of the American Association of Endodontists, $42 \%$ of clinicians reported that using $\mathrm{NaOCI}$ causes postoperative pain or serious complications at least once a year. ${ }^{8}$ That's why, researchers are in search of a more biocompatible irrigant.

It has been suggested currently that the use of the gel form of $\mathrm{NaOCI}$ is a potential option. ${ }^{9,10}$ Studies have reported that the solution and gel forms of $\mathrm{NaOCI}$ have a similar effect on dentin. In the study of Zand, et al. ${ }^{10}$ (2010) evaluating the smear layer removal activity of the solution and gel forms of $\mathrm{NaOCI}$, and the study of Garcia, et al. ${ }^{9}$ (2013) evaluating the effects of both forms on dentin microhardness, it has been reported that they have similar effects.

The effect of the gel form of $\mathrm{NaOCI}$ on postoperative pain has not been studied; therefore, this study compared the effects of using gel and solution forms of $5.25 \% \mathrm{NaOCI}$ in mandibular molar teeth with symptomatic irreversible pulpitis on postoperative pain. The null hypothesis was that there would be no difference between the gel and solution forms of NaOCI.

\section{Methodology}

\section{Study design, setting and sampling}

Ethical approval for the study was obtained from the Institutional Review Board and the Ethics Committee of the University. In this clinical trial, Consolidated Standards of Reporting Trials guidelines were followed (Figure 1) and the study protocol was registered on www.clinicaltrial.gov (Identifier: NCT04190355). Participation in the study was voluntary. All patients signed an informed consent form after aims, procedures, benefits and potential risks of the study were explained. The study was conducted by 4 postgraduate students with the same level of experience, trained in endodontic procedures (using rotary instruments, irrigation and canal filling). Power and Sample Size Calculation software version 3.1 .2 was used to calculate sample size. With $95 \%$ confidence, $95.1 \%$ test power and $d=0.1121$ effect size, the total sample size was determined to be 114 .

\section{Eligibility criteria}

The inclusion criteria were as follows:

Healthy individuals aged 18-45 without any systemic disease;

Mandibular molar teeth that were diagnosed with symptomatic irreversible pulpitis that showed prolonged response in the tooth even after the removal of the thermal and electric pulp test;

Teeth with all root canals inclined up to $25^{\circ}$ according to Schneider ${ }^{11}$ (1971) method, with two canals in the mesial root and a single canal in the distal root;

Patients with preoperative pain scores between moderate and severe (VAS, 4-10) according to the VAS scale.

The exclusion criteria were the following:

Patients having taken analgesics or antiinflammatory drugs in the past 12 hours;

Pregnant and lactating patients;

Teeth with radiologically proven periapical lesion;

Teeth that are too damaged to apply rubber dam;

Teeth with resorption, radiological evidence of calcification or open apices;

Patients with traumatic malocclusion;

Patients without occlusal contact.

114 patients were randomized into 2 groups based on the irrigation type during root canal preparation, using a computer program (available at 
CONSORT 2010 checklist of information to include when reporting a randomised trial*

Section/Topic Item No Checklist item

Reported on page No

Title and abstract

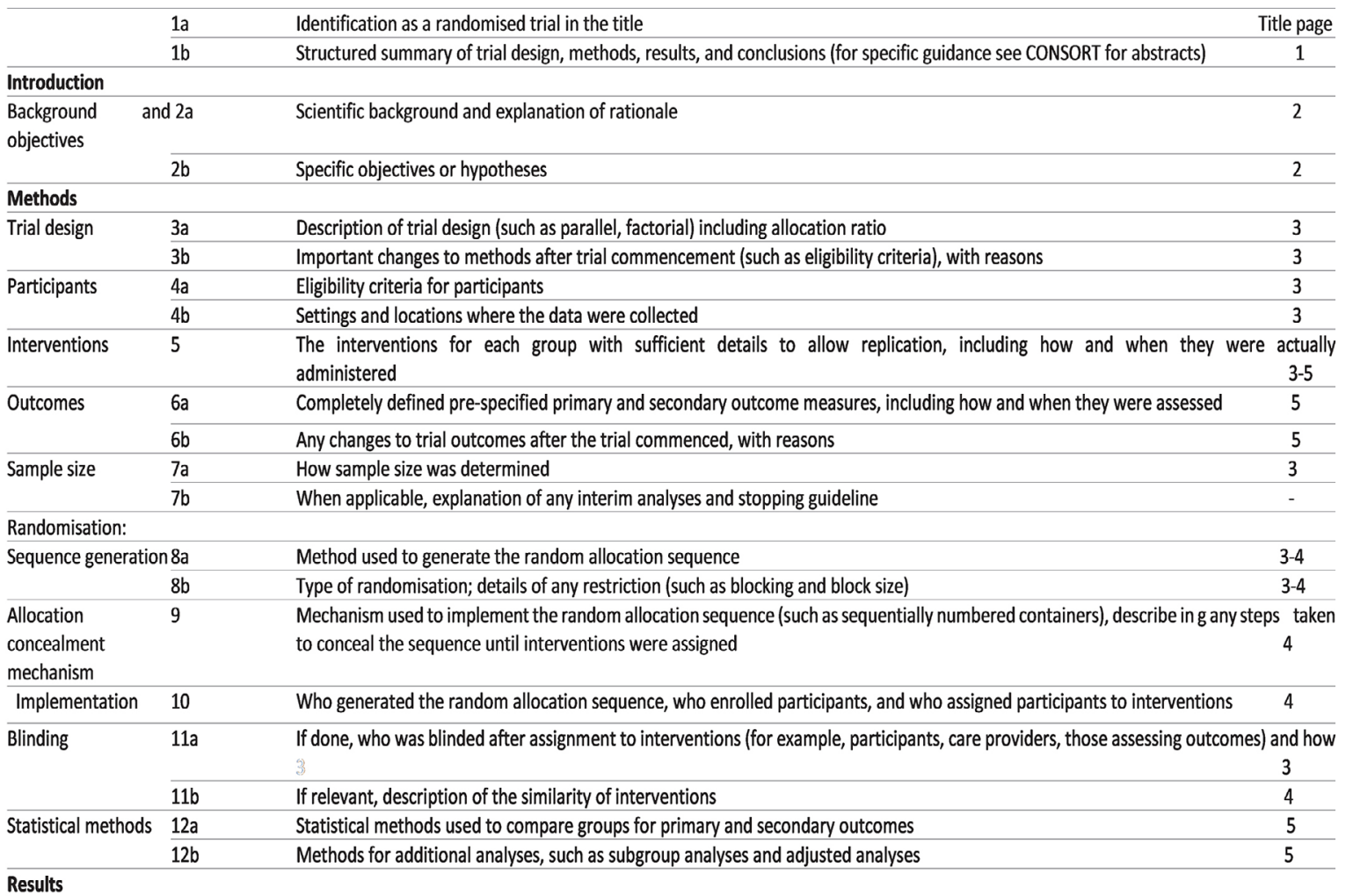

Participant flow (a13a $\quad$ For each group, the numbers of participants who were randomly assigned, received intended treatment, and were analysed for the diagram is strongly recommended primary outcome

\begin{tabular}{|c|c|c|}
\hline & $13 \mathrm{~b}$ & For each group, losses and exclusions after randomisation, together with reasons \\
\hline \multirow[t]{2}{*}{ Recruitment } & $14 a$ & Dates defining the periods of recruitment and follow-up \\
\hline & $14 b$ & Why the trial ended or was stopped \\
\hline Baseline data & 15 & A table showing baseline demographic and clinical characteristics for each group \\
\hline $\begin{array}{l}\text { Outcomes } \\
\text { estimation }\end{array}$ & and17a & For each primary and secondary outcome, results for each group, and the estimated effect size and its precision (such as $95 \%$ confidence \\
\hline Ancillary analyses & 18 & $\begin{array}{l}\text { Results of any other analyses performed, including subgroup analyses and adjusted analyses, distinguishing pre-specified from } \\
\text { exploratory }\end{array}$ \\
\hline Harms & 19 & All important harms or unintended effects in each group (for specific guidance see CONSORT for harms42) \\
\hline \multicolumn{3}{|l|}{ Discussion } \\
\hline Limitations & 20 & Trial limitations, addressing sources of potential bias, imprecision, and, if relevant, multiplicity of analyses \\
\hline Generalisability & 21 & Generalisability (external validity, applicability) of the trial findings \\
\hline Protocol & 24 & Where the full trial protocol can be accessed, if available \\
\hline Funding & 25 & Sources of funding and other support (such as supply of drugs), role of funders \\
\hline
\end{tabular}

Figure 1- The Consolidated Standards of Reporting Trials checklist

www.randomizer.org). Each group was randomly and equally divided. The allocation ratio was $1: 1$. In the study, patients were not informed about the division and they were blinded. However, the clinicians could not be blinded due to the nature of the study.

\section{Treatment procedure}

Root canal treatments of all patients were performed in a single session. Dental anesthesia was achieved using local anesthetic solution (Ultracain DS Fort, Hoechst-Marian Roussel, Frankfurt, Germany) containing 4\% articaine and 1:200000 epinephrine 
for inferior alveolar nerve blockade. After rubber dam isolation, endodontic access cavity was prepared using high-speed burs (Dentsply Maillefer, Ballaigues, Switzerland). The working length (WL) was determined using apex locator (Propex Pixi, Dentsply Maillefer) and confirmed to be $0.5-1 \mathrm{~mm}$ shorter than the "radiographic apex" by periapical radiographs. The root canals were mechanically prepared using ProTaper Next (Dentsply, Maillefer, Ballaigues, Switzerland) up to X3. All ProTaper Next files were used with an endodontic engine (X-Smart, Dentsply Sirona) at the torque and speed values recommended by the manufacturer. After reaching the WL with size-15 $\mathrm{K}$-type hand file, shaping was continued with brushing motion until the canal length was achieved with X1, X2 and $X 3$ files, respectively. The files were withdrawn at the point where resistance was met before torsional overload occurred and the work continued after the apical opening was checked with size-10 K-type hand file. All patients were divided into two groups based on irrigant used during root canal preparation ( $\mathrm{n}=$ 57): Group 1, 5.25\% NaOCI solution (Imicrly, Konya, Turkey), Group 2, 5.25\% Chloraxid gel.

Group 1 (NaOCI solution): The root canals were irrigated with $5 \mathrm{~mL}$ of $5.25 \% \mathrm{NaOCI}$.

Group 2 (NaOCI gel): Gel form of $5.25 \% \mathrm{NaOCI}$ (Chloraxid gel, Cercamed, Stalowo Wolo, Poland) was used. After covering the root canal files with $\mathrm{NaOCI}$ gel, they were placed in the root canal. During instrumentation canals were irrigated with $5 \mathrm{~mL}$ saline.

The irrigation procedure in all groups was performed with a NaviTip irrigation needle (30-G; Ultradent Products Inc, South Jordan, UT), placed $2 \mathrm{~mm}$ short of the working length. Once the shaping of the root canals was completed, according to the final irrigation procedure, all canals were irrigated with $5 \mathrm{~mL}$ of $17 \%$ EDTA solution (Imicryl, Konya, Turkey), $5 \mathrm{~mL}$ of $5.25 \% \mathrm{NaOCI}$ solution and $5 \mathrm{~mL}$ of saline, respectively. Root canals were dried with absorbent paper points (Denstply Maillefer, Baillagues, Switzerland). All groups were filled with gutta-percha (Denstply Maillefer, Baillagues, Switzerland) and AH Plus Sealer (Denstply Maillefer, Baillagues, Switzerland) root canal paste in the same session using the single-cone technique. After the quality of obturation was ensured with radiographs, coronal seal was provided with glass ionomer cement (Amalgomer, AHL, Kent, UK). The teeth was restored with composite resin (Filtek Z250, 3M ESPE, St. Paul, Minnesota, USA) and, then, occlusal contacts was checked and relieved where necessary. Each patient was prescribed $400 \mathrm{mg}$ of Ibuprofen and was instructed to take it every 8 hours when felt too severe and extremely unbearable pain to perform his daily activities.

\section{Postoperative pain assessment}

Visual analogue scale (VAS) was used for postoperative pain assessment. After endodontic treatment, all patients were given a detailed form to record their postoperative pain levels at the 6th, 24th, 48th, 72nd hours, and 1 week later. VAS assessment in this form was explained to the patients in detail, and they were asked to mark on the form the pain they felt at the 6th, 24th, 48th, 72nd hours, and 1 week later. One week after the treatment, patients were called by phone. The pain scores that the patients marked on the pain assessment form were learned and recorded in the patient file. According to the values recorded on the VAS, the pain levels were classified as no pain $(0)$, mild pain (1-3), moderate pain (4-6) and severe pain (7-10).

\section{Statistical analysis}

The data were analyzed by using IBM SPSS V23. The compatibility of the quantitative data to normal distribution was examined with the Kolmogorov Smirnov test. Chi-square test was conducted to compare categorical variables according to groups. Independent two sample t-test was performed for normally distributed data in comparison of quantitative variables according to between the two groups. Cochran $\mathrm{Q}$ test and Friedman test were used to examine the changes of categorical parameters within the group according to three or more time. Analysis results were presented as mean and standard deviation for quantitative data and as frequency (percentage) for categorical data. A p value of $<0.05$ was considered statistically significant.

\section{Results}

Of the 114 patients who participated in the study, 3 were not included in the analysis, as the instrument was broken in the root canal during root shaping (2 from the solution group and 1 from the gel group) and 7 were not accessible by phone ( 3 from the solution group and 4 from the gel group) (Figure 2 ). 


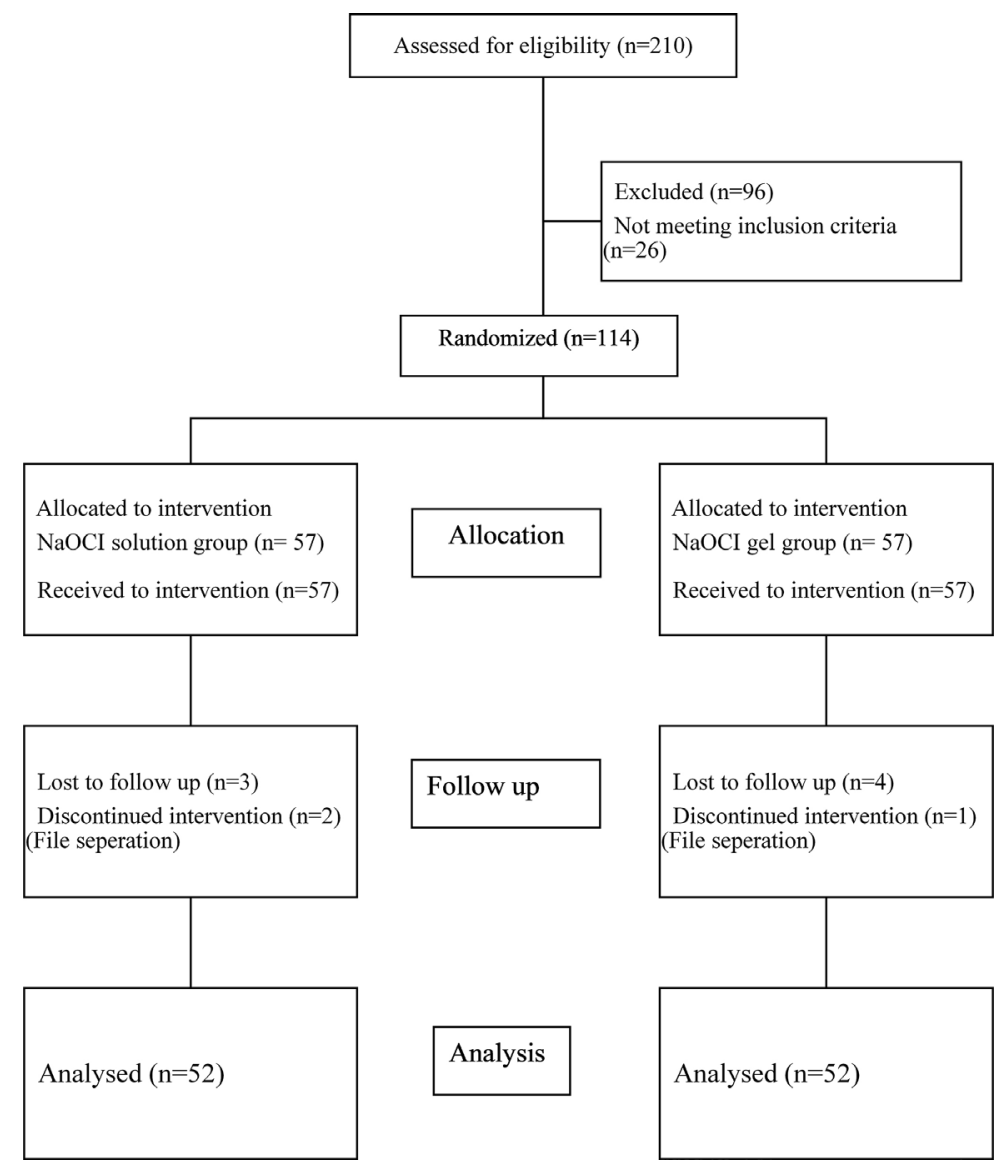

Figure 2- The Consolidated Standards of Reporting Trials 2010 flow diagram

Table 1- Comparison of Age, Gender and Pre-Operative Pain Values by Groups

\begin{tabular}{ccccc}
\hline & $\begin{array}{c}\text { NaOCI } \\
\text { Solution } \\
(\mathbf{n = 5 2 )}\end{array}$ & $\begin{array}{c}\mathbf{N a O C I} \\
(\mathbf{n}=52)\end{array}$ & Total & $\begin{array}{c}\mathbf{P} \\
\text { Value }\end{array}$ \\
\hline Age & $\begin{array}{c}31.25 \pm \\
\text { Gender }\end{array}$ & $\begin{array}{c}29,27 \pm \\
10.32\end{array}$ & $\begin{array}{c}30.26 \pm \\
9.58\end{array}$ & $0.294^{*}$ \\
Male & $24(46.2)$ & $25(48.1)$ & $49(47.1)$ & $0.844^{* *}$ \\
Female & $28(53.8)$ & $27(51.9)$ & $55(52.9)$ & \\
\hline
\end{tabular}

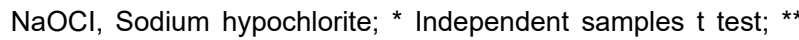
Chi-square test

Demographic data (gender and age) of the groups are shown in Table 1 . No statistically significant difference was found between the groups according to gender distribution ( $p>0.05)$.

Statistically significant difference was not observed between the groups according to distributions of pain levels at different times ( $p>0.05)$ (Table 2). A statistically significant difference was found between the distributions of pain levels measured at different times in the solution group $(p<0.001)$. A statistically significant difference was observed between the distributions of pain levels measured at different times in the gel group $(p<0.001)$. The mean and standard deviation of pain score of the groups are given in the table 3.

\section{Discussion}

The success of endodontic treatment depends on expanding and shaping the root canals, disinfecting and filling them fluid-tight. However, adequate disinfection cannot be achieved with mechanical preparation because of the complex anatomy of the root canals. Debris produced by the instruments during root canal treatment and the unshaped areas left untouched by the canal files affect the success of root canal treatment negatively by acting as a reservoir for microorganisms. Therefore, irrigation solutions should be used during and after the mechanical preparation of the root canals. ${ }^{12,13}$ Sodium hypochlorite is the most commonly used irrigant during root canal treatment. However, its cytotoxic effects when extruded into periapical tissues are clinically worrying. ${ }^{9}$ Currently, it has been reported that the use of the gel form rather than the solution form of $\mathrm{NaOCI}$ is similarly effective, so the clinical use of the former may be an appropriate 
Table 2- Comparison of Pain Levels Between Groups and Within Groups

\begin{tabular}{|c|c|c|c|c|c|c|c|}
\hline \multirow[t]{2}{*}{ Time } & \multirow[t]{2}{*}{ Pain } & \multicolumn{2}{|c|}{$\mathrm{NaOCl}$ Solution } & \multicolumn{2}{|c|}{$\mathrm{NaOCl}$ Gel } & \multirow{2}{*}{$\begin{array}{l}\text { Total } \\
\text { n (\%) }\end{array}$} & \multirow[t]{2}{*}{ P Value * } \\
\hline & & n (\%) & Pair Wise & n (\%) & Pair Wise & & \\
\hline \multirow{3}{*}{ Pre-Operative } & Mild & 7 (13.5) & \multirow{3}{*}{ a } & $5(9.6)$ & \multirow{3}{*}{ a } & $12(11.5)$ & \multirow{3}{*}{0.813} \\
\hline & Moderate & $38(73.1)$ & & $39(75.0)$ & & $77(74.0)$ & \\
\hline & Severe & $7(13.5)$ & & $8(15.4)$ & & 15 (14.4) & \\
\hline \multirow{4}{*}{6 hour } & No pain & $9(17.3)$ & \multirow{4}{*}{ b } & $20(38.5)$ & \multirow{4}{*}{ b } & $29(27.9)$ & \multirow{4}{*}{0.106} \\
\hline & Mild & $24(46.2)$ & & $20(38.5)$ & & $44(42.3)$ & \\
\hline & Moderate & $14(26.9)$ & & $9(17.3)$ & & $23(22.1)$ & \\
\hline & Severe & $5(9.6)$ & & $3(5.8)$ & & $8(7.7)$ & \\
\hline \multirow{4}{*}{24 hour } & No pain & $21(40.4)$ & \multirow{4}{*}{ c } & $29(55.8)$ & \multirow{4}{*}{ c } & $50(48.1)$ & \multirow{4}{*}{0.219} \\
\hline & Mild & $20(38.5)$ & & $17(32.7)$ & & $37(35.6)$ & \\
\hline & Moderate & 10 (19.2) & & $4(7.7)$ & & 14 (13.5) & \\
\hline & Severe & $1(1.9)$ & & $2(3.8)$ & & $3(2.9)$ & \\
\hline \multirow{4}{*}{48 hour } & No pain & $29(55.8)$ & \multirow{4}{*}{ d } & $36(69.2)$ & \multirow{4}{*}{$d$} & $65(62.5)$ & \multirow{4}{*}{0.556} \\
\hline & Mild & $19(36.5)$ & & $13(25)$ & & $32(30.8)$ & \\
\hline & Moderate & $3(5.8)$ & & $2(3.8)$ & & $5(4.8)$ & \\
\hline & Severe & $1(1.9)$ & & $1(1.9)$ & & $2(1.9)$ & \\
\hline \multirow{4}{*}{72 hour } & No pain & $41(78.8)$ & \multirow{4}{*}{ e } & $44(84.6)$ & \multirow{4}{*}{ e } & 85 (81.7) & \multirow{4}{*}{0.34} \\
\hline & Mild & $9(17.3)$ & & 7 (13.5) & & $16(15.4)$ & \\
\hline & Moderate & $2(3.8)$ & & --- & & $2(1.9)$ & \\
\hline & Severe & --- & & $1(1.9)$ & & $1(1)$ & \\
\hline \multirow{3}{*}{1 week } & No pain & $48(92.3)$ & \multirow{4}{*}{$f$} & $49(94.2)$ & \multirow{4}{*}{$f$} & 97 (93.3) & \multirow{4}{*}{0.603} \\
\hline & Mild & $3(5.8)$ & & $3(5.8)$ & & $6(5.8)$ & \\
\hline & Moderate & $1(1.9)$ & & --- & & $1(1)$ & \\
\hline P Value ${ }^{* *}$ & & $<0.001$ & & $<0.001$ & & & \\
\hline
\end{tabular}

$\mathrm{NaOCl}$, Sodium hypochlorite; n, Number of patient; ${ }^{*}$ Chi-square test; **Friedman testi; a-f, There is no difference between times with the same letter.

Table 3- The mean and standard deviations of pain score of groups at different time points

\begin{tabular}{ccc}
\hline & NaOCI Solution & NaOCI Gel \\
\hline 6 hour & $2,846 \pm 2,388$ & $2,096 \pm 2,411$ \\
24 hour & $1,885 \pm 2,111$ & $1,192 \pm 2,020$ \\
48 hour & $0,904 \pm 1,432$ & $0,712 \pm 1,499$ \\
72 hour & $0,385 \pm 1,051$ & $0,308 \pm 0,853$ \\
\hline week & $0,154 \pm 0,638$ & $0,077 \pm 0,334$ \\
\hline
\end{tabular}

$\mathrm{NaOCl}$, Sodium hypochlorite; $\mathrm{p}=0.345$. No significant differences were found between the groups

alternative to the latter. ${ }^{10,14}$

Many studies on postoperative pain levels exists in literature. Most of these studies have focused on different file systems, ${ }^{15}$ single-session and multisession treatment procedures, ${ }^{1,2}$ different irrigation concentrations ${ }^{16}$ and different irrigation activation systems. ${ }^{5}$ Topçuoğlu, et al. ${ }^{17}$ (2017)reported that the level of pain felt by the patients was higher than that of the patients in the manual file group compared to the Nair, et al. ${ }^{18}$ (2018) evaluated the effect of K-Files, Kedo-S and MTwo files on postoperative pain, they found the least pain scores in the MTwo group. Saba, et al. ${ }^{19}$ (2018) reported no difference in the effects of $2 \%$ chlorhexidine and $5.25 \%$ sodium hypochlorite solutions on postoperative pain. Farzaneh, et al. $^{20}$ (2018) reported that $2.5 \% \mathrm{NaOCI}$ solution showed lower pain levels in their studies, in which they evaluated the effect of $5.25 \% \mathrm{NaOCI}$ and $2.5 \% \mathrm{NaOCI}$ solution on postoperative pain. Moreover, Mostafa, et al. ${ }^{21}$ (2020) also reported that the $1.3 \% \mathrm{NaOCI}$ solution showed lower pain levels than 5.25\% NaOCI. Topçuoğlu, Topçuoğlu and Arslan ${ }^{22}$ (2018) reported in another study that apical positive irrigation (NaviTip) caused more pain than negative apical pressure irrigation system (EndoVac). To our knowledge, the effects of NaOCI's solution and gel forms on postoperative pain have not been evaluated in any study performed to date. Therefore, the effect of NaOCI's solution and gel forms on postoperative pain was compared in this study, and the null hypothesis was accepted.

Although no statistically significant difference 
was found between the distribution of postoperative pain levels of the gel and solution forms of $\mathrm{NaOCI}$ ( $p>0.05)$, at all times evaluated (6th, 24th, 48th, 72nd hours, and 1 week later), less pain has been observed in the gel group compared to the solution group. As the results show, it can be said that the gel form of $\mathrm{NaOCI}$ has a positive effect since its use during the chemomechanical preparation of the root canals caused lower levels of postoperative pain in patients.

Extrusion of dentin particles, necrotic pulp tissue and microorganisms from apical foramen to periapical tissues during chemomechanical preparation of root canals may increase postoperative pain by triggering an inflammatory reaction. ${ }^{23,24}$ Therefore, reducing the apical extrusion of debris and solution can reduce the degree of postoperative pain after endodontic treatment. Many studies in the literature evaluating the effect of irrigation techniques on the amount of apical extrusion of debris and irrigation solution exists, and these studies report that more debris is extruded with conventional needle irrigation. ${ }^{25-27}$ In addition, many studies in the literature evaluate the effect of irrigation activation techniques on postoperative pain. In these studies, higher levels of postoperative pain were reported in the treatments performed using conventional needles compared to sonic, ultrasonic and laser irrigation, and postoperative pain levels were associated with the amount of debris extrusion. 5,28 Although a lack of evidence is present, we think that lower postoperative pain levels with the use of the gel form of $\mathrm{NaOCI}$ in our study may be associated with the amount of apical debris extrusion, and this is in line with studies present in the literature. Further clinical studies are needed to evaluate the effect of the gel form of $\mathrm{NaOCI}$ on debris extrusion.

Although the gel form of $\mathrm{NaOCI}$ is advantageous to reduce postoperative pain, it is a concern whether the gel form of $\mathrm{NaOCI}$ is as effective as the smear removal and disinfection efficiency as the solution form. A limited number of studies focus on this subject in the literature review. Zand, et al. ${ }^{10}$ (2010) They reported that no difference between $\mathrm{NaOCI}$ solution and gel forms was observed in terms of smear removal efficiency. Abu Hasna, et al. ${ }^{29}$ (2020) also reported that no difference was found in their studies evaluating the effect on Enterococcus faecalis and Escherichia coli. Further studies evaluating the smear removal, disinfection and debris extrusion efficiency of $\mathrm{NaOCI}$ gel and solution forms are needed.
In our study, a statistically significant difference is present between the distributions of pain levels measured at different times in the gel group $(p<0.001)$. Pain levels of the gel group were obtained as $38,5 \%$ mild, $17.3 \%$ moderate, $5.8 \%$ severe at the 6th hour, $32.7 \%$ mild, $7.7 \%$ moderate, $3.8 \%$ severe at the 24 th hour, $25 \%$ mild, $3.8 \%$ moderate, $1.9 \%$ severe at the 48 th hour, $13.5 \%$ mild, $1.9 \%$ severe at the $72 \mathrm{nd}$ hour, 5.8\% mild 1 week later. A statistically significant difference was observed between the distributions of pain levels measured at different times in the solution group $(p<0.001)$. Pain levels of the solution group were obtained as $46.2 \%$ mild, $26.9 \%$ moderate, $9.6 \%$ severe at the 6th hour, $38.5 \%$ mild, $19.2 \%$ moderate, $1.9 \%$ severe at the 24 th hour, $36.5 \%$ mild, $5.8 \%$ moderate, $1.9 \%$ severe at the 48 th hour, $17.3 \%$ mild, $3.8 \%$ moderate at the 72 nd hour, $5.8 \%$ mild and $1.9 \%$ moderate 1 week later. In both groups, highest postoperative pain levels occurred in the first 6 hours, with decrease observed at the following 24th, 48th, 72nd hours and the end of 1 week. The results obtained in this study are consistent with other studies in the literature evaluating postoperative pain periods. $1,5,6,15,16$

Studies in the literature report that tooth type in different regions affects postoperative pain. Ali, et al. ${ }^{30}$ (2012) reported more pain in the mandibular region than in the maxillary region, while Arias, et al. $^{31}$ (2009) noted higher incidence of postoperative pain in mandibular molar teeth. This variability in pain may be due to the difference of canal configurations of teeth and their anatomy in the apical third. In this study, mandibular molar teeth were used regarding the studies in the literature. $2,6,15,26$

The painless treatment and post-treatment process provides patients with comfort and physicians with prestige. Therefore, pain research has become increasingly important in all health disciplines in recent years. However, concerns regarding the scientific communication of the sensation of pain exists. Because the sensation of pain is completely relative, varying from person to person. ${ }^{2}$ In previous studies evaluating postoperative pain observed after endodontic treatment, the VAS scale was used because it is simple, valid and reliable. ${ }^{1,3,5,16}$ VAS scale consists of numerical values. This makes it easier for patients to interpret and record their pain perceptions. ${ }^{1}$ In this study, the VAS scale was used to evaluate postoperative pain. Limitation of the present study was the blinding of 
endodontist was not possible due to the use of solution and gel form of $\mathrm{NaOCI}$.

One of the limitations of this study is that the patients refused to come to the control sessions because root canal treatment was completed in one session. Therefore, pain levels were collected by phone calls. Although the clinicians could not be blinded due to the nature of the study, the researcher who made the phone calls could be blinded about the method of treatment.

\section{Conclusion}

Within the limitations of the study, using gel or solution forms of $\mathrm{NaOCI}$ during chemomechanical preparation of root canals, resulted in similar postoperative pain. For both formulations, pain level decreased over time.

\section{Conflict of interest}

The authors deny any conflicts of interest related to this study.

\section{Authors' contributions}

Özlek, Esin: Conceptualization (Lead); Formal analysis (Lead); Investigation (Equal); Methodology (Equal); Project administration (Lead); Writing-original draft (Lead). GÜNDÜZ, Hüseyin: Conceptualization (Supporting); Data curation (Equal); Investigation (Equal); Methodology (Equal). Kadi, Gizem: Data curation (Equal); Investigation (Equal). Tasan, Ahmet: Data curation (Equal). Akkol, Elif: Data curation (Supporting); Formal analysis (Supporting).

\section{References}

1- Neelakantan P, Sharma S. Pain after single-visit root canal treatment with two single-file systems based on different kinematics--a prospective randomized multicenter clinical study. Clin Oral Investig. 2015;19(9):2211-7. doi:10.1007/s00784-015-1448-x

2- Wang C, Xu P, Ren L, Dong G, Ye L. Comparison of post-obturation pain experience following one-visit and two-visit root canal treatment on teeth with vital pulps: a randomized controlled trial. Int Endod J. 2010;43(8):692-7. doi:10.1111/j.1365-2591.2010.01748.x 3- Ulin C, Magunacelaya-Barria M, Dahlén G, Kvist T. Immediate clinical and microbiological evaluation of the effectiveness of $0.5 \%$ versus $3 \%$ sodium hypochlorite in root canal treatment: a quasi-randomized controlled trial. Int Endod J. 2020;53(5):591-603. doi:10.1111/ iej.13258
4- Seltzer S, Naidorf IJ. Flare-ups in endodontics: I. etiological factors. 1985. J Endod. 2004;30(7):476-81; discussion 475. doi:10.1097/00004770-200407000-00005

5- Topçuoğlu HS, Topçuoğlu G, Arslan H. The effect of different iIrrigation agitation techniques on postoperative pain in mandibular molar teeth with symptomatic irreversible pulpitis: a randomized clinical trial. J Endod. 2018;44(10):1451-6. doi:10.1016/j.joen.2018.06.008 6- Yılmaz K, Tüfenkçi $P$, Adıgüzel $M$. The effects of QMix and EndoActivator on postoperative pain in mandibular molars with nonvital pulps: a randomized clinical trial. Clin Oral Investig. 2019;23(11):417380. doi:10.1007/s00784-019-02856-6

7- Pontes F, Pontes H, Adachi P, Rodini C, Almeida D, Pinto D Jr. Gingival and bone necrosis caused by accidental sodium hypochlorite injection instead of anaesthetic solution. Int Endod J. 2008;41(3):267-70. doi:10.1111/j.1365-2591.2007.01340.x

8- Kleier DJ, Averbach RE, Mehdipour O. The sodium hypochlorite accident: experience of diplomates of the American Board of Endodontics. J Endod. 2008;34(11):1346-50. doi:10.1016/j. joen.2008.07.021

9- Garcia AJ, Kuga MC, Palma-Dibb RG, Só MV, Matsumoto MA, Faria G, et al. Effect of sodium hypochlorite under several formulations on root canal dentin microhardness. J Investig Clin Dent. 2013;4(4):229-32. doi:10.1111/j.2041-1626.2012.00158.x

10- Zand V, Lotfi M, Rahimi S, Mokhtari H, Kazemi A, Sakhamanesh $\mathrm{V}$. A comparative scanning electron microscopic investigation of the smear layer after the use of sodium hypochlorite gel and solution forms as root canal irrigants. J Endod. 2010;36(7):1234-7. doi:10.1016/j. joen.2010.02.033

11- Schneider SW. A comparison of canal preparations in straight and curved root canals. Oral Surg Oral Med Oral Pathol. 1971;32(2):271-5. doi:10.1016/0030-4220(71)90230-1

12- Haupt F, Meinel M, Gunawardana A, Hülsmann M. Effectiveness of different activated irrigation techniques on debris and smear layer removal from curved root canals: a SEM evaluation. Aust Endod J. 2020;46(1):40-6. doi: 10.1111/aej.12342

13- Pinheiro SL, Silva CC, Silva LA, Cicotti MP, Bueno CE, Fontana $\mathrm{CE}$, et al. Antimicrobial efficacy of $2.5 \%$ sodium hypochlorite, $2 \%$ chlorhexidine, and ozonated water as irrigants in mesiobuccal root canals with severe curvature of mandibular molars. Eur J Dent. 2018;12(1):94-9. doi: 10.4103/ejd.ejd_324_17

14- Faria G, Viola KS, Coaguila-Llerena $H$, Oliveira LR, Leonardo RT, Aranda-García AJ, et al. Penetration of sodium hypochlorite into root canal dentine: effect of surfactants, gel form and passive ultrasonic irrigation. Int Endod J. 2019;52(3):385-92. doi:10.1111/iej.13015 15- Nekoofar MH, Sheykhrezae MS, Meraji N, Jamee A, Shirvani A, Jamee $\mathrm{J}$, et al. Comparison of the effect of root canal preparation by using WaveOne and ProTaper on postoperative pain: a randomized clinical trial. J Endod. 2015;41(5):575-8. doi:10.1016/j.joen.2014.12.026 16- Verma N, Sangwan P, Tewari S, Duhan J. Effect of different concentrations of sodium hypochlorite on outcome of primary root canal treatment: a randomized controlled trial. J Endod. 2019;45(4):357- 63. doi:10.1016/j.joen.2019.01.003

17- Topçuoğlu G, Topçuoğlu HS, Delikan E, Aydınbelge M, Dogan S. Postoperative pain after root canal preparation with hand and rotary files in primary molar teeth. Pediatr Dent. 2017;39(3):192-6.

18- Nair M, Jeevanandan G, Vignesh R, Subramanian EM. Comparative evaluation of post-operative pain after pulpectomy with $\mathrm{K}$-files, Kedo-S files and MTwo files in deciduous molars -a randomized clinical trial. Braz Dent Sci. 2018;21:411-7. doi:10.14295/bds.2018.v21i4.1617 19- Saba K, Maxood A, Abdullah S, Riaz A, Uddin S. Comparison of frequency of pain in root canal treatment using sodium hypochlorite and chlorhexidine as root canal irrigants. J Pak Med Assoc. 2018;68(9):1334-8. 
20- Farzaneh S, Parirokh M, Nakhaee N, Abbott PV. Effect of two different concentrations of sodium hypochlorite on postoperative pain following single-visit root canal treatment: a triple-blind randomized clinical trial. Int Endod J. 2018;51 Suppl 1:e2-e11. doi:10.1111/ iej.12749

21- Mostafa M, El-Shrief YAI, Anous WI, Hassan MW, Salamah FT, El Boghdadi RM, et al. Postoperative pain following endodontic irrigation using $1.3 \%$ versus $5.25 \%$ sodium hypochlorite in mandibular molars with necrotic pulps: a randomized double-blind clinical trial. Int Endod J. 2020;53(2):154-66. doi:10.1111/iej.13222

22- Topçuoğlu HS, Topçuoğlu G, Arslan H. The effect of apical positive and negative pressure irrigation methods on postoperative pain in mandibular molar teeth with symptomatic irreversible pulpitis: a randomized clinical trial. J Endod. 2018;44(8):1210-5. doi:10.1016/j. joen.2018.04.019

23- Doğanay Yıldız E, Arslan $\mathrm{H}$. The effect of blue thermal treatment on endodontic instruments and apical debris extrusion during retreatment procedures. Int Endod J. 2019;52(11):1629-34. doi:10.1111/iej.13161 24- Siqueira JF Jr, Rôças IN, Favieri A, Machado AG, Gahyva SM, Oliveira $\mathrm{JC}$, et al. Incidence of postoperative pain after intracanal procedures based on an antimicrobial strategy. J Endod. 2002;28(6):457-60. doi:10.1097/00004770-200206000-00010

25- Jezeršek M, Jereb T, Lukač N, Tenyi A, Lukač M, Fidler A. Evaluation of apical extrusion during novel Er:YAG laser-activated irrigation modality. Photobiomodul Photomed Laser Surg. 2019;37(9):544-50. doi:10.1089/photob. 2018.4608
26- Romualdo PC, Oliveira KM, Nemezio MA, Küchler EC, Silva RA, Nelson-Filho $P$, et al. Does apical negative pressure prevent the apical extrusion of debris and irrigant compared with conventional irrigation? A systematic review and meta-analysis. Aust Endod J. 2017;43(3):12937. doi:10.1111/aej.12162

27- Barbosa-Ribeiro M, Arruda-Vasconcelos R, Fabretti FL, Silva EJ, DeDeus G, Gomes BP. Evaluation of apically extruded debris using positive and negative pressure irrigation systems in association with differenti. Braz Dent J. 2018;29(2):184-8. doi: 10.1590/0103-6440201801750 28- Uslu G, Özyürek T, Yılmaz K, Gündoğar M, Plotino G. Apically extruded debris during root canal instrumentation with reciproc blue, HyFlex EDM, and XP-endo shaper nickel-titanium files. J Endod. 2018;44(5):856-9. doi:10.1016/j.joen.2018.01.018

29- Abu Hasna A, Pereira Da Silva L, Pelegrini FC, Ferreira CL, Oliveira LD, Carvalho CA. Effect of sodium hypochlorite solution and gel with/without passive ultrasonic irrigation on Enterococcus faecalis, Escherichia coli and their endotoxins. F1000Res. 2020;9:642. doi:10.12688/f1000research.24721.1

30- Ali SG, Mulay S, Palekar A, Sejpal D, Joshi A, Gufran H. Prevalence of and factors affecting post-obturation pain following single visit root canal treatment in Indian population: a prospective, randomized clinical trial. Contemp Clin Dent. 2012;3(4):459-63. doi:10.4103/0976237x.107440

31- Arias A, Azabal M, Hidalgo JJ, de la Macorra JC. Relationship between postendodontic pain, tooth diagnostic factors, and apical patency. J Endod. 2009;35(2):189-92. doi:10.1016/j.joen.2008.11.014 